\title{
The function of medication beliefs as mediators between personality traits and adherence behavior in people with asthma
}

This article was published in the following Dove Press journal:

Patient Preference and Adherence

21 October 2013

Number of times this article has been viewed

\section{Malin Axelsson ${ }^{1,2}$ \\ Christina Cliffordson ${ }^{2}$ \\ Bo Lundbäck' \\ Jan Lötvall'}

'Krefting Research Centre, Institute of Medicine, Internal Medicine and

Clinical Nutrition, Sahlgrenska

Academy, University of Gothenburg, Gothenburg, Sweden; ${ }^{2}$ Department of Nursing, Health and Culture, University West, Trollhättan, Sweden
Correspondence: Malin Axelsson Krefting Research Centre, Institute of Medicine, Internal Medicine and Clinical Nutrition, Sahlgrenska Academy, University of Gothenburg, Box 424, SE-405 30 Gothenburg, Sweden

$\mathrm{Tel}+46317866716$

Fax +46317866730

Email malin.axelsson@gu.se
Background: There is evidence that both personality traits and personal beliefs about medications affect adherence behavior. However, limited research exists on how personality and beliefs about asthma medication interact in influencing adherence behavior in people with asthma. To extend our knowledge in this area of adherence research, we aimed to determine the mediating effects of beliefs about asthma medication between personality traits and adherence behavior.

Methods: Asthmatics ( $\mathrm{n}=516)$ selected from a population-based study called West Sweden Asthma Study completed the Neuroticism, Extraversion and Openness to Experience FiveFactor Inventory, the Medication Adherence Report Scale, and the Beliefs about Medicines Questionnaire. Data were analyzed using confirmatory factor analysis and structural equation modeling.

Results: Three of the five investigated personality traits - agreeableness, conscientiousness, and neuroticism - were associated with both concerns about asthma medication and adherence behavior. Concerns functioned as a partial mediator for the influencing effects of agreeableness, conscientiousness, and neuroticism on adherence behavior.

Conclusion: The findings suggest that personality traits could be used to identify individuals with asthma who need support with their adherence behavior. Additionally, targeting concerns about asthma medication in asthmatics with low levels of agreeableness or conscientiousness or high levels of neuroticism could have a favorable effect on their adherence behavior.

Keywords: adherence, individual differences, medication concerns, health behavior

\section{Introduction}

Individuals' perceptions about medication most likely have an impact on adherence behavior. ${ }^{1-3}$ For instance, people who express beliefs that the prescribed medication is necessary for their health are more inclined to adhere to the prescription. In contrast, those who are concerned about side effects or becoming addicted are more likely to deviate from their prescriptions. ${ }^{1-3}$ It has previously been reported that people with asthma expressed more concerns about their medication than did people who had been prescribed medications for renal, cardiac, or cancer conditions. ${ }^{1}$ With regard to asthma medication treatment, Menckeberg et $\mathrm{al}^{4}$ stated that the lowest adherence scores were found among asthmatics who had been classified as being skeptical or indifferent toward the prescribed medication. The highest adherence scores were found among asthmatics who had been classified as having an accepting attitude toward the medication. Ponieman et $\mathrm{al}^{5}$ reported that having concerns about side effects or finding it difficult to follow the treatment regimen constituted risks for poor adherence. In contrast, 
being confident in one's ability to use the medication, and believing that it was important to use the medication during asymptomatic periods, reduced the risk of poor adherence.

Personality contributes to people's thoughts, feelings, and behavior. ${ }^{6}$ Consequently, personality also influences an individual's perceptions of health ${ }^{7}$ and health outcomes ${ }^{8-10}$ as well as their health-related behaviors, for example, adherence behavior. ${ }^{10-16}$ According to the Five-Factor Model (FFM), ${ }^{17}$ personality can be described using five broad and bipolar personality traits: agreeableness, conscientiousness, extraversion, neuroticism, and openness to experience. The personality traits are rather stable in adulthood, they have been identified in various cultures, and are evident in both women and men. ${ }^{17}$ With regard to adherence behavior, people with lower levels of agreeableness ${ }^{16}$ or conscientiousness ${ }^{11-13,16}$ or higher levels of neuroticism ${ }^{15,16}$ seem more inclined to display nonadherent behavior. People with lower levels of agreeableness are more predisposed to being skeptical, reluctant, and less cooperative. People with lower levels of conscientiousness are more disorganized and non-goal oriented in disposition. People with higher levels of neuroticism could be described as anxious, moody, and less stress tolerant. ${ }^{18}$

Approximately 300 million people throughout the world have asthma; despite the variation in prevalence across countries $(1 \%-18 \%)$, asthma is regarded as a global burden. ${ }^{19}$ Asthma causes substantial consequences for both society and the individual, for instance, in terms of costs for health care, medication, work absenteeism, and reduced health-related quality of life. ${ }^{19}$ Through better disease control and reduction in exacerbations, the consequences of asthma could be reduced. Inadequate adherence to a treatment regimen is regarded as one of the most common causes of poor disease control in people with asthma. ${ }^{19}$ Research on adherence to asthma medication treatment has shown that approximately $50 \%$ of those who had been prescribed long-term treatment displayed nonadherence, at least part of the time. ${ }^{20,21}$ Such lapse in managing asthma could constitute an increased risk for unsatisfactory disease control, ${ }^{20,22}$ leading to individual consequences such as limitations in daily life, nighttime awakenings, exacerbations, impaired lung function, ${ }^{19}$ and poor health-related quality of life. ${ }^{23}$ Therefore, promotion of adherence could be regarded as a cost-cutting measure. ${ }^{24}$

Both personality and beliefs about medication are factors known to influence adherence, but little is known about their interaction in relation to adherence behavior. Because personality contributes to people's thinking, feeling, and behaving, ${ }^{6}$ and because personality traits are rather stable constructs, ${ }^{17}$ we hypothesized that personality would be shown to affect people's perceptions about their medication, which in turn would have an impact on their adherence behavior. In order to extend our knowledge in this specific area of adherence research, our aim was to determine the mediating effects of beliefs about asthma medication between personality traits and adherence behavior.

\section{Material and methods Participants}

The sample was selected from a population-based study conducted in western Sweden, the West Sweden Asthma Study. ${ }^{25}$ The sampling procedure is illustrated in Figure 1. The participants $(n=516)$ consisted of adults with asthma (60\% women), who were born between 1933 and 1991 (mean age 47.36 years, standard deviation 15.6 years). The participants were invited to take part in the current study when they visited the research center to participate in the clinical part of the West Sweden Asthma Study between 2009 and 2012. The participants received written information combined with verbal information about the current study as well as questionnaires. Most participants completed the questionnaires at the research center, and participants who chose to bring the questionnaires home for completion received a prepaid reply envelope. Two reminders were sent to nonresponders. A completed and returned questionnaire was regarded as consent to participate. The study was approved by the regional research ethics board at the University of Gothenburg (593-08, December 18, 2008).

\section{Measures}

The data were collected using questionnaires on personality traits, beliefs about asthma medication, adherence behavior, and prescribed asthma medication treatment. Sociodemographic data were collected through structured interviews. The Neuroticism, Extraversion and Openness to Experience Five-Factor Inventory was used to assess the FFM personality traits. The inventory consists of 60 items, 12 for each personality trait, scaled 1-5. ${ }^{18}$ The Beliefs about Medicines Questionnaire was used to assess beliefs about prescribed asthma medications. The questionnaire consists of ten items, scaled 1-5. Five items measure concerns about the asthma medication, ie, worries about side effects, long-term effects, and becoming addicted. The remaining five items measure beliefs about the necessity of the asthma medication, ie, that both present and future health depends on the asthma medication and that medication prevents a worsening of the disease. ${ }^{26}$ The Medication Adherence Report Scale consists of five items that measure adherence behavior with regard to the extent to which a person forgets to take, 


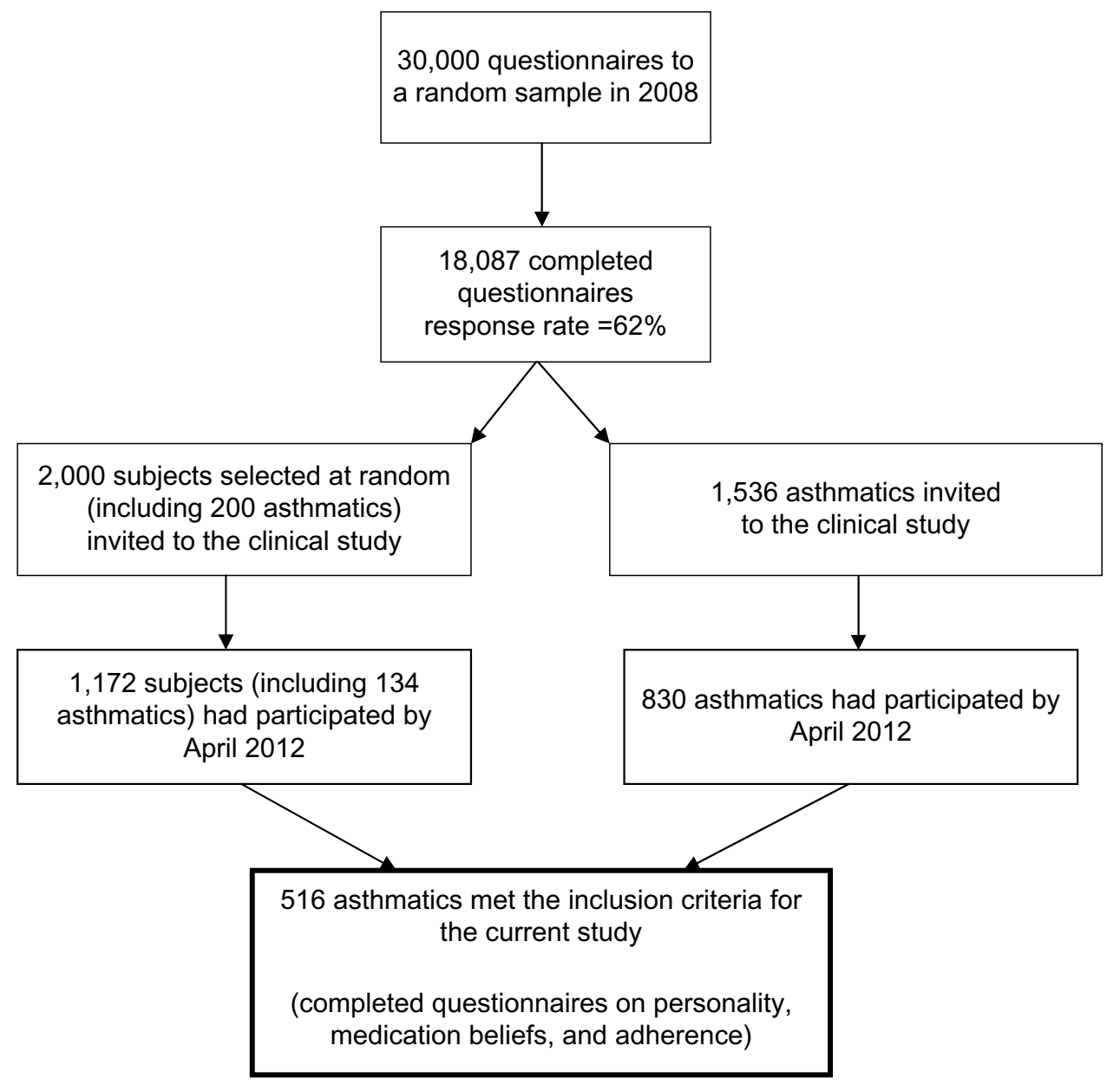

Figure I Sampling procedure.

alters the dosage of and stops taking the asthma medication, misses out doses and takes less than instructed. The five items are scaled $1-5 .{ }^{27}$ The Cronbach's alpha scores for all scales are presented in Table 1.

\section{Model testing}

In a mediator model, a variable functions as a mediator when it explains the association between the independent variable

Table I Number of items, reliability for the scales, and mean values and standard deviations (SD)

\begin{tabular}{llll}
\hline Scale & $\begin{array}{l}\text { Number } \\
\text { of items }\end{array}$ & $\begin{array}{l}\text { Cronbach's } \\
\text { alpha }\end{array}$ & $\begin{array}{l}\text { Mean } \\
\text { (SD) }\end{array}$ \\
\hline Agreeableness & 12 & 0.71 & $46.3(5.7)$ \\
Conscientiousness & 12 & 0.81 & $46.0(6.5)$ \\
Extraversion & 12 & 0.80 & $42.6(7.3)$ \\
Neuroticism & 12 & 0.85 & $28.3(8.4)$ \\
Openness to experience & 12 & 0.70 & $39.6(6.6)$ \\
Concerns & 5 & 0.83 & $9.8(4.5)$ \\
Necessity & 5 & 0.90 & $15.7(5.6)$ \\
Adherence & 5 & 0.75 & $18.7(6.2)$ \\
\hline
\end{tabular}

and the dependent variable. To qualify as a mediator in the current study, the following criteria had to be met: ${ }^{28}$

1. The independent variable accounted for the variation in the mediator.

2. The mediator accounted for the variation in the dependent variable.

3. If the association between step 1 and step 2 were controlled for, the former significant correlation between the independent and dependent variable went to zero or decreased.

A zero is the strongest demonstration of a mediating effect. A decrease in the previous association was regarded as a partial mediating effect, which indicated that, like other phenomena, there are several factors underlying adherence, not only personality and medication beliefs. Therefore a decrease rather than a zero may be more realistic. ${ }^{28}$

One path model for each personality trait was constructed. The personality traits were treated as independent variables, adherence as a dependent variable, and medication belief as a mediator. In the path model, it was first determined 
whether the independent variable, ie, the personality trait, had a direct effect on the dependent variable, ie, adherence. Second, whether or not the independent variable accounted for the variation in the mediator was checked. If so, the first criterion was met. Thereafter, it was determined whether the mediator accounted for the variation in the dependent variable. If so, the second criterion was met. In the next step, it was checked whether the previous significant association between the independent and the dependent variable decreased or went to zero in the path model when paths to and from the mediator were introduced. If so, the third and final criterion was met. ${ }^{28}$ Finally, in order to determine the total effect on the independent variable, the effects from the different paths were summed.

\section{Analysis}

In order to investigate the mediating effects of beliefs about asthma medication between personality traits and adherence behavior, confirmatory factor analysis and structural equation modeling technique with latent variables were used.

Latent variables reflect hypothetical constructs and are estimated based on the relations among two or more observed variables (indicators). In areas such as the assessment of traits, it is implausible to assume that the conceptual variables can be measured without appreciable error. ${ }^{29}$ Measurement of traits always includes error components. The use of latent variables permits the estimation of relationships among observed variables and theoretically interesting constructs that are free from the effects of such measurement unreliability. Factor analysis divides the variance in the observed variables into three variance components: first, true score common variance related to the construct or constructs of interest; second, a component that is reliable and specific to the variable; and third, a variance component that represents measurement error. That is to say, one way to solve the problem of measurement error is to use a latent variable approach. ${ }^{30}$

\section{Goodness of fit}

The analyses were carried out using the statistical modeling program Mplus (Muthén \& Muthén, Los Angeles, CA, USA), version $5^{31}$ under the STREAMS ${ }^{32}$ environment. As measures of model fit, the $\chi^{2}$ goodness-of-fit test, the root mean square error of approximation, and the standardized root mean square residual assessment were used. The root mean square error of approximation is strongly recommended as a tool when evaluating model fit, as it takes into account both the number of observations and the number of free parameters. An acceptable model fit is indicated by values of less than 0.08 , while values of less than 0.05 imply a good model fit. Standardized root mean square residual can range from $0-1$, where 0 is indicative of a perfect model fit, and values of 0.08 or smaller indicate an acceptable model fit. ${ }^{33}$ When evaluating model fit, the reasonableness of parameter estimates was also considered.

\section{Missing data}

The total amount of internal missing data for the seven scales was $1,127(6.7 \%)$ scores distributed across the 75 items. To include all of the collected information, the missing data modeling procedure implemented in the Mplus program was used. ${ }^{34}$ This modeling procedure is based on the assumption that the data is "missing at random", which is a much less restrictive assumption than the assumption that the data is "missing completely at random." The basic principle is that subsets of cases with a particular pattern of missing observations each have a separate covariance matrix, where the matrices are combined into one total matrix. ${ }^{32,34}$ That implies that the procedure yields unbiased estimates when the missing value is random, given the information in the data. The fact that there are relatively high interrelations among the observed variables provides good possibilities to satisfy the missing at random assumption..$^{35,36}$

\section{Results \\ Medication beliefs as mediators}

Three of the five investigated personality traits - agreeableness, conscientiousness, and neuroticism - were associated with both adherence behavior and concerns about the asthma medication. Openness to experience was associated with concerns, but no associations were identified between this personality trait and adherence. No associations were found between extraversion and adherence and medication beliefs. The belief that the asthma medication was a necessity for present and future health was associated with adherence behavior, but not with any of the personality traits (Table 2). Consequently, the variables extraversion, openness to experience, and beliefs that the asthma medication was a necessity were excluded from further analysis. Reports on prescribed asthma medication treatment are presented in Table 3. The amount of internal missing data across the five remaining scales (agreeableness, conscientiousness, neuroticism, concerns, and adherence) and 46 items was 783 scores or $5.9 \%$. Three path models with the personality traits as independent variables, adherence as a dependent variable, and medication concerns as a mediator were constructed. The goodness of fit was acceptable in all three models (Table 4). 
Table 2 Standardized factor loadings between latent variables for personality traits, medication beliefs, and adherence

\begin{tabular}{|c|c|c|c|c|c|c|}
\hline \multirow[t]{2}{*}{ Scale } & \multicolumn{2}{|c|}{ Adherence } & \multicolumn{2}{|c|}{ Concern } & \multicolumn{2}{|c|}{ Necessity } \\
\hline & & t-value & & t-value & & $t$-value \\
\hline Agreeableness & 0.175 & 2.902 & -0.193 & -3.410 & 0.076 & 1.353 \\
\hline Conscientiousness & 0.148 & 2.634 & -0.104 & -1.964 & 0.088 & 1.717 \\
\hline Extraversion & -0.044 & -0.780 & -0.011 & -0.203 & -0.051 & -0.984 \\
\hline Neuroticism & -0.146 & -2.685 & 0.249 & 4.949 & -0.025 & -0.479 \\
\hline Openness & -0.051 & -0.880 & 0.114 & 2.087 & 0.051 & 0.946 \\
\hline Necessity & 0.413 & 8.464 & 0.295 & 6.216 & & \\
\hline Concern & -0.148 & -2.628 & & & & \\
\hline
\end{tabular}

Note: Significant associations are in bold.

\section{Agreeableness}

The path model including agreeableness, concern, and adherence showed a significant path between agreeableness and adherence (0.151), meaning that agreeableness had a direct effect on adherence. Furthermore, the paths between agreeableness and concern $(-0.192)$ and concern and adherence $(-0.118)$ were also significant, which means that concern functioned as a partial mediator for the influencing effect of agreeableness on adherence (Figure 2). The total effect on adherence was the direct and mediating effect together $(-0.192) \times(-0.118)+0.151=0.174$, which corresponded with the standardized correlation coefficient between agreeableness and adherence (Table 2). Therefore, concern qualified as a mediator for the influencing effect of agreeableness on adherence.

\section{Conscientiousness}

The path model with conscientiousness as the independent variable showed a significant path between conscientiousness and adherence (0.133), meaning that conscientiousness had a direct effect on adherence (Figure 3 ). The paths between conscientiousness and concern $(-0.104)$ and concern and adherence $(-0.133)$ were significant as well,

Table 3 Prescribed asthma medications

\begin{tabular}{ll}
\hline & $\mathbf{n}(\%)$ \\
\hline $\begin{array}{l}\text { Regular inhalation therapy } \\
\text { Short-acting } \beta 2 \text {-agonist }\end{array}$ & $123(28.9 \%)$ \\
Long-acting $\beta 2$-agonist & $36(8.9 \%)$ \\
Corticosteroids & $132(31.1 \%)$ \\
$\begin{array}{l}\text { Corticosteroids + long-acting } \beta 2 \text {-agonist } \\
\text { (combination therapy) }\end{array}$ & $114(26.8 \%)$ \\
Inhalation therapy as required & \\
Short-acting $\beta 2$-agonist & \\
Long-acting $\beta 2$-agonist & $311(73.2 \%)$ \\
Corticosteroids & $27(6.4 \%)$ \\
Corticosteroids + long-acting $\beta 2$-agonist & $66(15.5 \%)$ \\
(combination therapy) & $57(13.4 \%)$ \\
\hline
\end{tabular}

which means that concern partially mediated the effect of conscientiousness on adherence. The total effect on adherence consisted of the direct and mediated effect together $(-0.104) \times(-0.133)+0.133=0.147$, which corresponded with the standardized correlation coefficient between conscientiousness and adherence (Table 2). Therefore, concern qualified as a mediator for the influencing effect of conscientiousness on adherence.

\section{Neuroticism}

The path model with neuroticism as the independent variable showed that this personality trait had a direct effect on adherence (Figure 4), as there was a significant path between these two variables $(-0.114)$. The paths between neuroticism and concern $(0.250)$ and adherence $(-0.122)$ were significant too, which means that concern functioned as a partial mediator for the influencing effect of neuroticism on adherence. The total influencing effect of neuroticism on adherence was the direct and mediating effect together $0.250 \times(-0.122)+(-0.114)=-0.145$, which corresponded with the standardized correlation coefficient between neuroticism and adherence (Table 2). Therefore, concern qualified as a mediator for the influencing effect of neuroticism on adherence.

\section{Discussion}

The current findings reinforce the significance of both personality and medication beliefs in relation to adherence

Table 4 Goodness of fit indexes for models A, B, and C

\begin{tabular}{lllll}
\hline Model & $\begin{array}{l}\chi^{2} \\
\text { value }\end{array}$ & df & RMSEA & SRMR \\
\hline A: Agreeableness & 564.907 & 206 & $0.058(0.052-0.064)^{*}$ & 0.056 \\
B: Conscientiousness & 554.373 & 206 & $0.057(0.052-0.063)^{*}$ & 0.060 \\
C: Neuroticism & 505.189 & 206 & $0.053(0.047-0.059)^{*}$ & 0.050 \\
\hline
\end{tabular}

Note: *Represents $90 \%$ confidence intervals.

Abbreviations: $d f$, degrees of freedom; RMSEA, root mean square error of approximation; SRMR, standardized root mean square residual. 


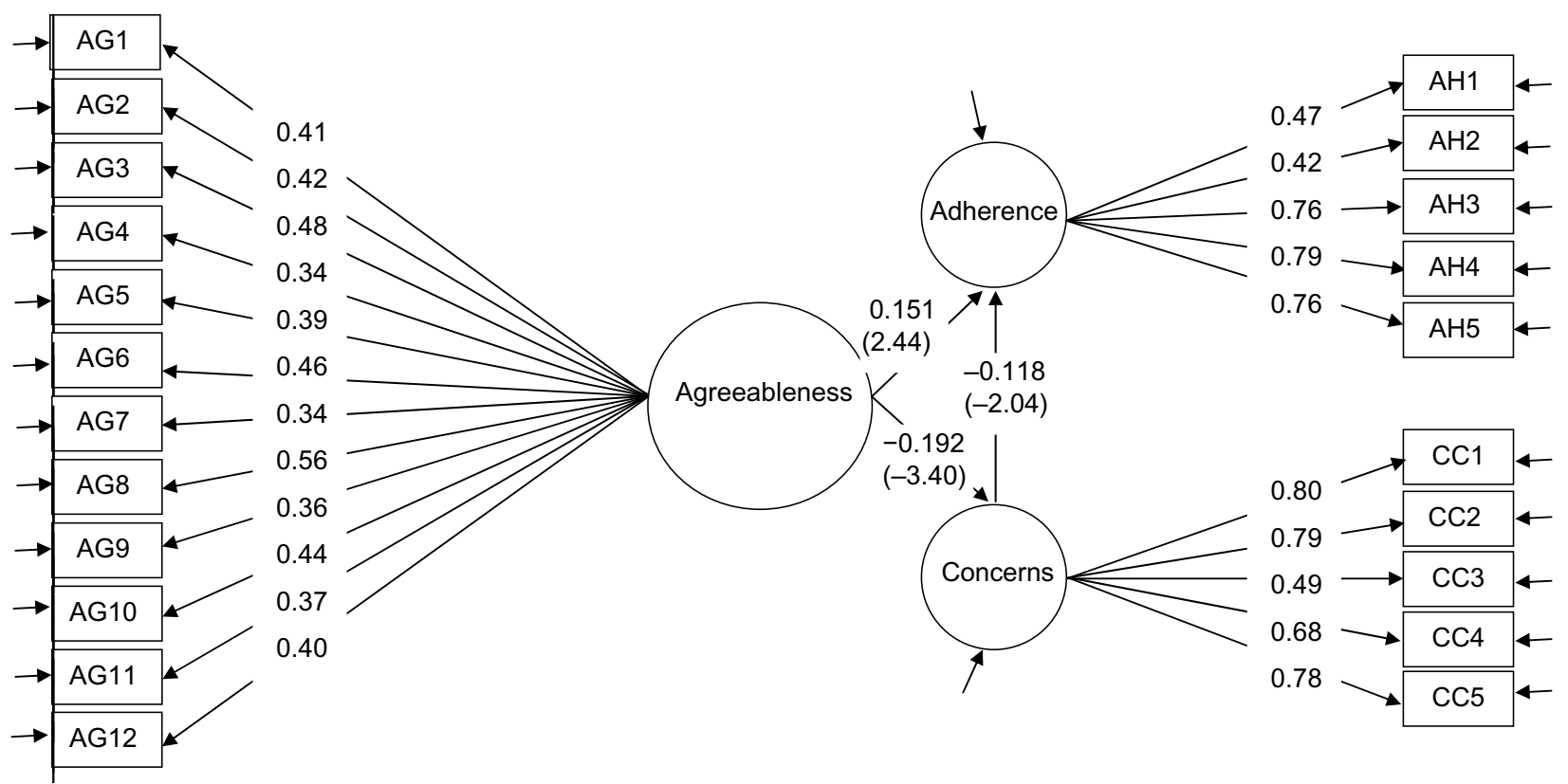

Figure 2 Standardized factor loadings ( $t$-values) for the structural equation model, containing the agreeableness (AG), concerns (CC), and adherence (AH) scales. Notes: All estimates are significant; $t$-values $>1.96$ were significant at 0.05 level.

behavior. However, the study is unique in that it explores the joint effect of personality and medication beliefs on adherence to asthma medication. Three of the five investigated personality traits were associated with both perceived concerns about the asthma medication and adherence behavior: agreeableness, conscientiousness, and neuroticism. Thus, medication beliefs functioned as a mediator for the influencing effects of three of the five FFM personality traits on adherence behavior.

The main focus of the present study was on evaluating the function of medication beliefs as a mediator between personality and adherence behavior. Based on the findings,

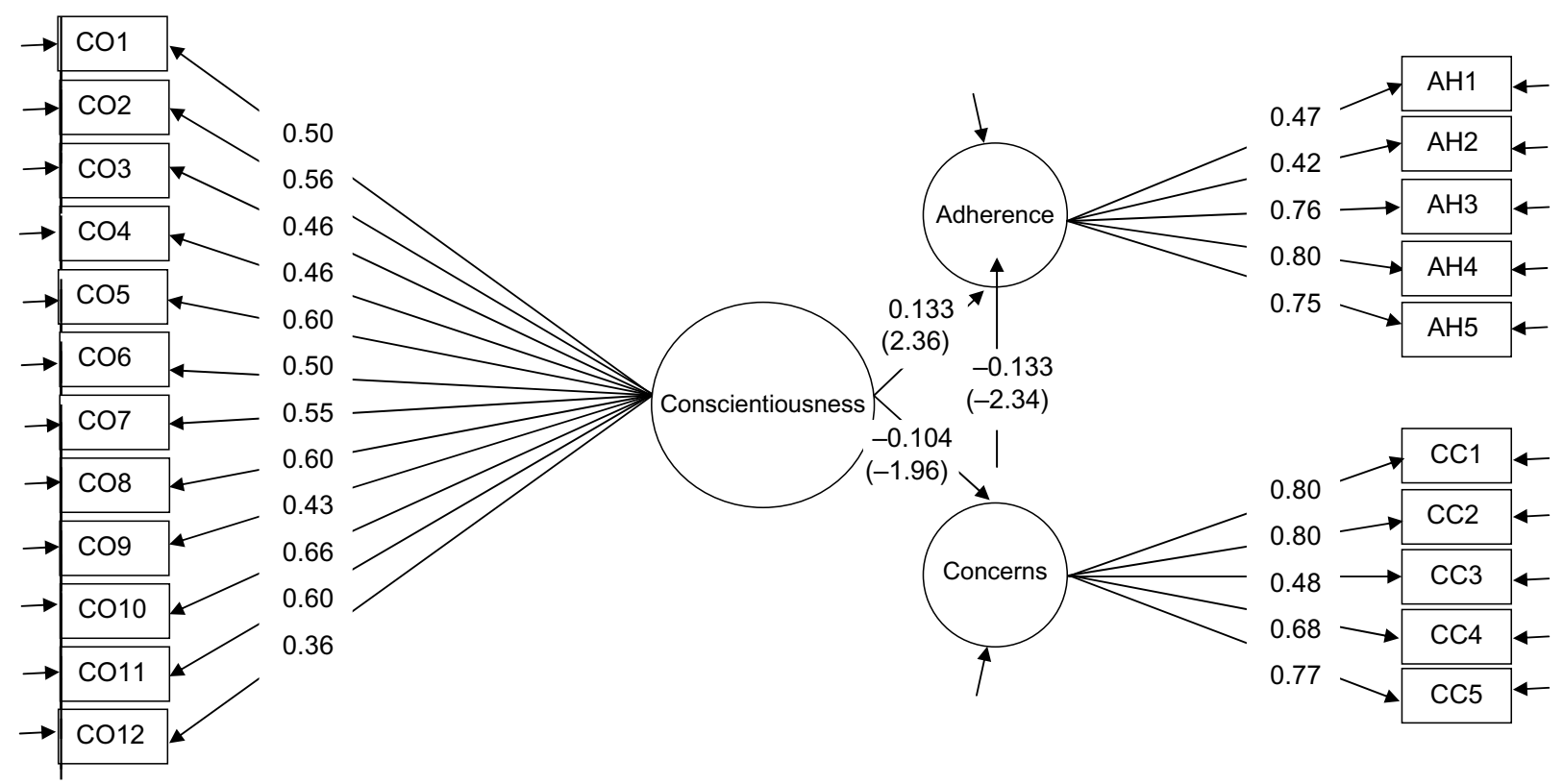

Figure 3 Standardized factor loadings ( $t$-values) for the structural equation model, containing the conscientiousness (CO), concerns (CC), and adherence (AH) scales. Notes: All estimates are significant; $t$-values $>1.96$ were significant at 0.05 level. 


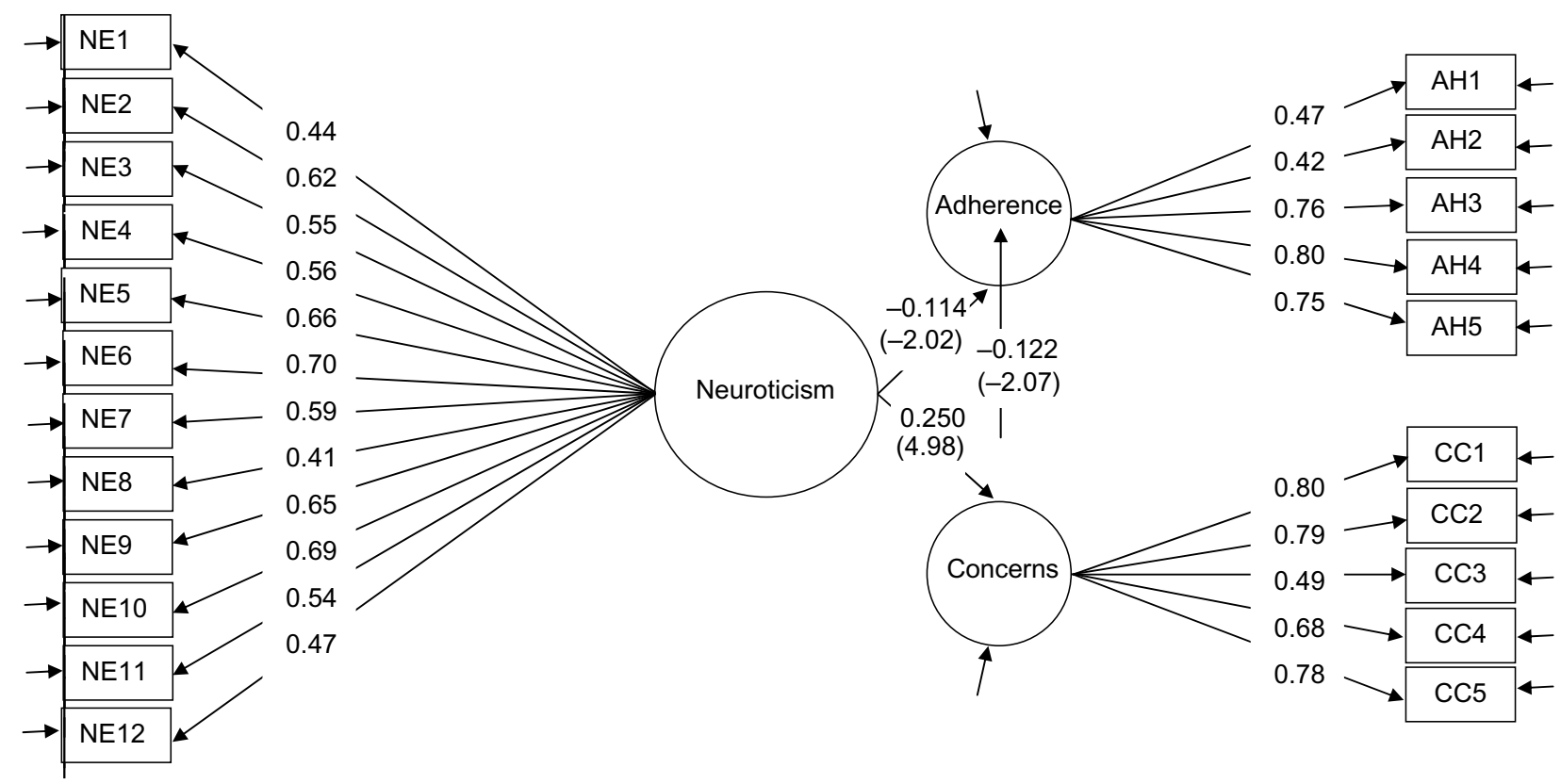

Figure 4 Standardized factor loadings ( $t$-values) for the structural equation model, containing the neuroticism (NE), concerns (CC), and adherence (AH) scales. Notes: All estimates are significant; $t$-values $>1.96$ were significant at 0.05 level.

it would seem reasonable to argue that personality can be used to identify individuals with asthma who are at risk for poor adherence to asthma medication therapy. In the path models, we were able to show the direct effects of three personality traits on adherence, revealing that asthmatics with low levels of agreeableness or conscientiousness or high levels of neuroticism tend to be more inclined to display poor adherence behavior. At the same time, they expressed more concerns about the medication. Therefore, the findings suggest that addressing medication concerns in people with these personality characteristics, with a view to reducing their concerns, could have a favorable effect on their adherence behavior. Previous interventions addressing beliefs about asthma medication have proved useful in increasing adherence in people with asthma. ${ }^{37,38}$ With the addition of personality in similar interventions, people at risk for displaying poor adherence could be identified, and assistance could be provided to those most in need. Furthermore, an awareness of the importance of patients' individual differences could guide and inspire health care personnel in their encounters with patients with different personality characteristics when providing adherence support.

The present study confirmed previous findings in this specific area of adherence research. First, by showing that previously reported associations between the FFM personality traits and adherence ${ }^{11-13,15,16}$ are also valid for adherence behavior in people with asthma. Second, the current study identified associations between medication beliefs and adherence to asthma medication similar to associations reported previously. ${ }^{4,5}$ Additionally, the study discerned associations between personality traits and beliefs about asthma medication. Participants with low levels of agreeableness or conscientiousness or high levels of neuroticism had more concerns about their prescribed asthma medication. These findings both confirm and contradict our previous study ${ }^{39}$ in which we showed that neuroticism was positively associated with medication concerns, which is in line with the current study. However, our previous study ${ }^{39}$ also identified associations between extraversion and concerns and between conscientiousness and necessity, which we did not find in the current study. These dissimilarities may be due to sample size and/or sampling procedure. The current study has its origin in a population-based study, meaning that the present sample has better representativeness than our previous study. ${ }^{39}$ However, further investigation may be needed before any conclusions can be drawn.

People with low levels of agreeableness are by nature more predisposed to being skeptical and distrusting ${ }^{18}$ - personality characteristics that could influence their thinking about asthma medication. Low levels of conscientiousness are associated with a low degree of motivation in goal-directed behavior, and ${ }^{18}$ less conscientious persons also seem to be generally prone to living a less healthy lifestyle. ${ }^{40}$ 
These tendencies could possibly explain these individuals' negative attitude toward asthma medication in the current study. Moreover, participants with high levels of neuroticism were more prone to having concerns about their asthma medication. High scores on this personality trait are associated with behavioral tendencies, like being worried, ${ }^{18}$ which could explain their proneness to experiencing medicationrelated concerns.

It is to be noted that the strongest correlation between adherence and the other investigated variables was found between necessity and adherence. This finding is in line with previous research, ${ }^{1,4}$ which emphasized that beliefs that the asthma medication is a necessity for the present and future health, for instance, also constitute a significant target in efforts to improve adherence. However, based on the current findings, we also need to take patients' different personality characteristics and concerns with their asthma medication into consideration.

\section{Methodological considerations}

One strength of the current study is that the sample was selected from a population-based study, which increases the possibility of applying the present findings to individuals with asthma in general. Nevertheless, an additional strength was the use of structural equation modeling to test the theoretical relationships between personality traits, medication beliefs, and adherence behavior. Path models provide an estimation of the effects between the variables in the theoretical model. ${ }^{41}$ Use of this statistical analysis enables the identification of mediators that predict the effect of an independent variable on a dependent variable prior to an intervention. If a hypothesized model turns out to be correct, it can be assumed that intervening to change the mediator would in turn affect the outcome. ${ }^{42}$ For that reason, it is important that the hypothesized models be designed only after careful theoretical consideration. ${ }^{41}$ We used personality traits as independent variables, meaning that the other variables did not influence the traits. This assumption was made based on the theoretical consideration that, according to the FFM, personality traits have a strong biological base, leading to a high degree of stability in personality during adulthood. ${ }^{17}$ Another reason for treating the personality traits as independent variables was that personality influences our thoughts, feelings, and behavior. ${ }^{6}$ Treating medication beliefs as mediators was based on previous research describing beliefs about asthma medication as predictors of adherence. ${ }^{5}$ As regards reliability, the Cronbach's alpha scores for the scales were acceptable, although in two cases they were either exactly at or only slightly above the normal cut-off point (0.70) for reliability. However, because latent variables are free from sources of influence irrelevant to the hypothetical construct intended to be captured, the problem associated with a somewhat mediocre alpha estimate does not arise, provided that the model fit is acceptable. Indeed, the model fit for the three investigated hypothetic models was acceptable. ${ }^{33}$ One weakness in the study was the sparse data on the socioeconomic characteristics of the participants, but all available data such as age, sex, and prescribed asthma medication were shown. Another possible limitation of the study was that adherence was measured using self-reports, which could result in overestimation of adherence. However, considering the study design, self-report was the most suitable method of assessing adherence behavior.

\section{Conclusion}

Both personality and beliefs about asthma medication play a role in adherence behavior in people with asthma. Addressing concerns about asthma medication and trying to reduce such concerns, primarily in asthmatics with low levels of agreeableness or conscientiousness or high levels of neuroticism, would most likely lead to positive effects on adherence.

\section{Acknowledgments}

The study was funded by unrestricted grants from the VBG GROUP Centre for Asthma and Allergy Research, Herman Krefting Foundation against Asthma and Allergy and GlaxoSmithKline.

\section{Disclosure}

The authors report no conflicts of interest in this work.

\section{References}

1. Horne R, Weinman J. Patients' beliefs about prescribed medicines and their role in adherence to treatment in chronic physical illness. J Psychosom Res.1999;47(6):555-567.

2. Clifford S, Barber N, Horne R. Understanding different beliefs held by adherers, unintentional nonadherers, and intentional nonadherers: application of the Necessity-Concerns Framework. J Psychosom Res. 2008;64(1):41-46.

3. Phatak HM, Thomas J. Relationships between beliefs about medications and nonadherence to prescribed chronic medications. Ann Pharmacother. 2006;40(10):1737-1742.

4. Menckeberg TT, Bouvy ML, Bracke M, et al. Beliefs about medicines predict refill adherence to inhaled corticosteroids. J Psychosom Res. 2008;64(1):47-54.

5. Ponieman D, Wisnivesky JP, Leventhal H, Musumeci-Szabó TJ, Halm EA. Impact of positive and negative beliefs about inhaled corticosteroids on adherence in inner-city asthmatic patients. Ann Allergy Asthma Immunol. 2009;103(1):38-42.

6. Pervin LA, Cervone D. Personality: Theory and Research. 10th ed. Hoboken, NJ: Wiley; 2008.

7. Goodwin R, Engstrom G. Personality and the perception of health in the general population. Psychol Med. 2002;32(2):325-332. 
8. Chapman B, Duberstein P, Lyness JM. Personality traits, education, and health-related quality of life among older adult primary care patients. J Gerontol B Psychol Sci Soc Sci. 2007;62(6):P343-P352.

9. Dubayova T, Nagyova I, Havlikova E, et al. Neuroticism and extraversion in association with quality of life in patients with Parkinson's disease. Qual Life Res. 2009;18(1):33-42.

10. Axelsson M, Emilsson M, Brink E, Lundgren J, Torén K, Lötvall J. Personality, adherence, asthma control and health-related quality of life in young adult asthmatics. Respir Med. 2009;103(7):1033-1040.

11. Christensen AJ, Smith TW. Personality and patient adherence: correlates of the five-factor model in renal dialysis. J Behav Med. 1995;18(3): 305-313.

12. Stilley CS, Sereika S, Muldoon MF, Ryan CM, Dunbar-Jacob J. Psychological and cognitive function: predictors of adherence with cholesterol lowering treatment. Ann Behav Med. 2004;27(2):117-124.

13. O’Cleirigh C, Ironson G, Weiss A, Costa PT Jr. Conscientiousness predicts disease progression (CD4 number and viral load) in people living with HIV. Health Psychol. 2007;26(4):473-480.

14. Ediger JP, Walker JR, Graff L, et al. Predictors of medication adherence in inflammatory bowel disease. Am J Gastroenterol. 2007;102(7): 1417-1426.

15. Bruce JM, Hancock LM, Arnett P, Lynch S. Treatment adherence in multiple sclerosis: association with emotional status, personality, and cognition. J Behav Med. 2010;33(3):219-227.

16. Axelsson M, Brink E, Lundgren J, Lötvall J. The influence of personality traits on reported adherence to medication in individuals with chronic disease: an epidemiological study in West Sweden. PLoS One. 2011;6(3):e18241.

17. McCrae RR, Costa PT Jr. Personality in Adulthood: A Five-Factor Theory Perspective. 2nd ed. New York, NY: Guilford Press; 2003.

18. Costa PT Jr, McCrae RR. Revised NEO Personality Inventory (NEOPI-R) and NEO Five-Factor Inventory (NEO-FFI) Professional Manual. Odessa, FL: Psychological Assessment Resources; 1992.

19. Global Strategy for Asthma Management and Prevention [webpage on the Internet]. Global Initiative for Asthma (GINA); 2011. Available from: http://www.ginasthma.org/. Accessed November 29, 2012.

20. Clatworthy J, Price D, Ryan D, Haughney J, Horne R. The value of self-report assessment of adherence, rhinitis and smoking in relation to asthma control. Prim Care Respir J. 2009;18(4):300-305.

21. Latry P, Pinet M, Labat A, et al. Adherence to anti-inflammatory treatment for asthma in clinical practice in France. Clin Ther. 2008; 30 Spec No:1058-1068.

22. Krishnan JA, Riekert KA, McCoy JV, et al. Corticosteroid use after hospital discharge among high-risk adults with asthma. Am J Respir Crit Care Med. 2004;170(12):1281-1285.

23. Lisspers K, Ställberg B, Hasselgren M, Johansson G, Svärdsudd K. Quality of life and measures of asthma control in primary health care. J Asthma. 2007;44(9):747-751.

24. Bender BG, Rand C. Medication non-adherence and asthma treatment cost. Curr Opin Allergy Clin Immunol. 2004;4(3):191-195.
25. Lötvall J, Ekerljung L, Rönmark EP, et al. West Sweden Asthma Study: prevalence trends over the last 18 years argues no recent increase in asthma. Respir Res. 2009;10:94.

26. Horne R, Weinman J, Hankins M. The beliefs about medicines questionnaire: the development and evaluation of a new method for assessing the cognitive representation of medication. Psychol Health. 1999;14(1):1-24.

27. Horne R, Weinman J. Self-regulation and self-management in asthma: exploring the role of illness perceptions and treatment beliefs in explaining non-adherence to preventer medication. Psychol Health. 2002;17(1):17-32.

28. Baron RM, Kenny DA. The moderator-mediator variable distinction in social psychological research: conceptual, strategic, and statistical considerations. J Pers Soc Psychol. 1986;51(6):1173-1182.

29. Maruyama GM. Basics of Structural Equation Modelling. Thousand Oaks, CA: Sage Publications; 1998.

30. Gustafsson JE, Stahl PA. STREAMS 1.7 User's Guide. Mölndal, Sweden: Multivariate Ware; 1997.

31. Muthén LK, Muthén BO. Mplus User's Guide. Fifth Edition. Los Angeles, CA: Muthén and Muthén; 1998-2007.

32. Gustafsson JE, Stahl PA. STREAMS 3.0 User's Guide. Mölndal, Sweden: Multivariate Ware; 2005.

33. Brown TA. Confirmatory Factor Analysis for Applied Research. New York, NY: Guilford Press; 2006

34. Muthén B, Kaplan D, Hollis M. On structural equation modeling with data that are not missing completely at random. Psychometrika. 1987;52(3):431-462.

35. Allison PD. Missing data techniques for structural equation modeling. J Abnorm Psychol. 2003;112(4):545-557.

36. Schafer JL, Graham JW. Missing data: our view of the state of the art. Psychol Methods. 2002;7(2):147-177.

37. Park J, Jackson J, Skinner E, Ranghell K, Saiers J, Cherney B. Impact of an adherence intervention program on medication adherence barriers, asthma control, and productivity/daily activities in patients with asthma. J Asthma. 2010;47(10):1072-1077.

38. Bender BG, Apter A, Bogen DK, et al. Test of an interactive voice response intervention to improve adherence to controller medications in adults with asthma. J Am Board Fam Med. 2010;23(2):159-165.

39. Emilsson M, Berndtsson I, Lötvall J, et al. The influence of personality traits and beliefs about medicines on adherence to asthma treatment. Prim Care Respir J. 2011;20(2):141-147.

40. Bogg T, Roberts BW. Conscientiousness and health-related behaviors: a meta-analysis of the leading behavioral contributors to mortality. Psychol Bull. 2004;130(6):887-919.

41. Schumacker RE, Lomax RG. A Beginner's Guide to Structural Equation Modeling. 2nd ed. Mahwah, NJ: Lawrence Erlbaum Associates; 2004.

42. Mackinnon DP, Farichild AJ, Fritz MS. Mediation analysis. Annu Rev Psychol. 2007;58:593-614.
Patient Preference and Adherence

\section{Publish your work in this journal}

Patient Preference and Adherence is an international, peer-reviewed, open access journal focusing on the growing importance of patient preference and adherence throughout the therapeutic continuum. Patient satisfaction, acceptability, quality of life, compliance, persistence and their role in developing new therapeutic modalities and compounds to

\section{Dovepress}

optimize clinical outcomes for existing disease states are major areas of interest. This journal has been accepted for indexing on PubMed Central. The manuscript management system is completely online and includes a very quick and fair peer-review system. Visit http://www.dovepress.com/ testimonials.php to read real quotes from published authors. 